\title{
Analysis of financial failure risk in Borsa Istanbul lodging companies with Beaver model
}

\author{
Erdinç Karadeniz ${ }^{1}$, Cemile Öcek ${ }^{2}$
}

\begin{abstract}
Depending on the political, economic, social and technological developments in the world, it is observed that lodging companies have difficulties to sustain their existence. Nowadays, lodging companies should have a strong financial structure in order to continue their activities successfully. In this context, it is important to measure and manage the risk of financial failure in terms of lodging companies. The purpose of this research is to measure the financial failure risks of the lodging companies traded in Borsa Istanbul (BIST) for the years 2012-2017 by Beaver model. For this purpose, 11 lodging companies traded in Borsa Istanbul (BIST) were analyzed according to the variables of the Beaver model. As a result of the analysis, it was concluded that some of the BIST lodging companies were insufficient to meet their long-term obligations, that their net working capital was negative, their profitability was low, their cash flows were insufficient, and their financial leverage levels were effective.
\end{abstract}

Keywords: Financial Failure, Financial Failure Risk, Beaver Model, Lodging Companies, Borsa Istanbul.

\section{Borsa İstanbul konaklama işletmelerinde finansal başarısızlık riskinin Beaver Modeli kullanılarak analizi}

\begin{abstract}
$\ddot{O} z$
Dünyadaki siyasi, ekonomik, sosyal ve teknolojik gelişmelere bağlı olarak konaklama işletmelerinin varlıklarını sürdürebilmek için zorluklar yaşadığ gözlemlenmektedir. Günümüzde konaklama işletmelerinin faaliyetlerini başarll bir şekilde devam ettirebilmeleri için güçlü finansal bir yapıya sahip olmaları gerekmektedir. Bu bağlamda, finansal başarısızlık riskinin konaklama işletmeleri açısından ölçülmesi ve yönetilmesi önem arz etmektedir. Bu araştırmanın amacı, Borsa İstanbul'da (BIST) işlem gören konaklama işletmelerinin 2012-2017 ylllarına ait finansal başarısızlık risklerinin Beaver modeliyle ölçülmesidir. Bu amaçla Borsa İstanbul'da (BİST) işlem gören 11 konaklama işletmesi, Beaver modelinin değişkenlerine göre analiz edilmiştir. Analiz sonucunda, BİST konaklama işletmelerinin bazılarının uzun vadeli yükümlülüklerini karşılamada yetersiz olduğu, net çalışma sermayelerinin negatif olduğu, karlılıklarının düşük olduğu, nakit akışlarının yetersiz olduğu, finansal kaldıraç düzeylerini ise etkin kullanmaya çalıştıkları sonucuna ulaşılmışıtır.
\end{abstract}

Anahtar sözcükler: Finansal Başarısızlık, Finansal Başarısızlık Riski, Beaver Modeli, Konaklama İşletmeleri, Borsa İstanbul.

Geliş Tarihi : :27.09.2018

Kabul Tarihi : :01.03.2019

Alıntı için: Karadeniz, E., Öcek, C. (2019). Borsa İstanbul konaklama işletmelerinde finansal başarısızlık riskinin Beaver Modeli kullanilarak analizi. Journal of Tourism Theory and Research, 5(2), 99-111.

\footnotetext{
${ }^{1}$ Doç. Dr., Mersin Üniversitesi Turizm Fakültesi Turizm İşletmeciliği Bölümü. E-Posta:ekaradeniz@mersin.edu.tr

2 Sorumlu Yazar, Mersin Üniversitesi Sosyal Bilimler Enstitüsü Turizm İşletmeciliği Anabilim Dalı Doktora Programı, EPosta:cemile_ocek@hotmail.com
} 


\section{Giriş}

Son y1llarda yaşanan küreselleşmeye bağlı olarak sürekli değişen ve ağırlaşan rekabet şartları, ömürleri sonsuz olarak kabul edilen işletmelerin varlıklarını sürdürülebilirlik temelinde devam ettirmelerinde zorluklar yaşamalarına hatta finansal başarısızlık yaşayarak iflas ile karşı karşıya gelmelerine neden olabilmektedir. Turizm sektöründe faaliyet gösteren konaklama işletmeleri, yatırım aşamasında büyük miktarda sabit varlığa ihtiyaç duyan, faaliyet aşamasında genişleme ve modernizasyon yatırımlarına gereksinim duyan; risk ve belirsizliğin her zaman var olduğu işletmelerdir. Bahsedilen unsurların konaklama işletmeleri üzerindeki etkilerinin önceden belirlenerek buna uygun önlemler alınması, işletmelerin sürdürülebilirlikleri açısından gerekli görülmektedir. Bu bağlamda finansal başarısızlık ve iflas riskinin konaklama işletmeleri açısından da ölçülmesi ve yönetilmesi büyük önem arz etmektedir.

Başarısızlık, işletmelerin büyüklükleri ve bulundukları ülkelerin gelişmişlik düzeyleri ne olursa olsun karşılaşabilecekleri bir sorundur. İşletmelerin temel ya da yan faaliyet alanlarında faaliyetlerini gerçekleştirememesi, yükümlülüklerin vadesi geldiğinde ödenememesi hatta iflasına kadar birçok durum başarısızlık olarak tanımlanabilmektedir (Aydın, Başar ve Coşkun, 2014: 323). Bir başka tanıma göre başarısızlık, işletmelerin çevrelerine uyum sağlayamamaları, durgunluk, örgütsel gerileme, küçülme, iflas, işletmenin faaliyetinin durması ve işletmenin kapatılması olarak tanımlanmaktadır (Weitzel ve Jonsson, 1989: 91). İşletmeler açısından başarısızlık; ekonomik başarısızlık ve finansal başarısızlık olarak iki durumda ortaya çıkmaktadır (Ceylan, 2001: 340). Ekonomik başarısızlık, belirli düzeyde risk içeren yatırılan sermaye üzerinden sağlanan getiri oranında, eşdeğer yatırımlardaki getiri oranından dikkat çekici derecede ve sürekliliği devam eden bir şekilde düşüş yaşanmasıdır (Özdemir, 2011: 37). Finansal başarısızlık ise işletmenin faaliyetlerinin durması, iflas halinde olması, icra veya haciz sorunlarının yaşanması, tasfiye yaşanması, işletmeye kayyum atanmas1 ve konkordato yapılmas1 gibi durumlardan herhangi birini ya da tamamını yaşaması olarak tanımlanmaktadır (Altman ve Hotchkiss, 2006: 4). Genel olarak finansal başarısızlık kavramı, işletmelerin fi- nansal başarısını belirlemek için kullanılan çalışmalarda iflas yerine kullanılan bir kavram olarak görülmektedir. Bunun nedeni ise finansal başarısızlık kavramının, iflas kavramına göre daha geniş kapsamlı olmasıdır. (Aktaş, 1993: 8).

Genel olarak finansal açıdan başarısızlık, finansal yükümlülüklerin yerine getirilmemesi olarak tanımlanabilmektedir (Aydın, Başar ve Coşkun, 2014: 325). Finansal başarısızlık, işletmelerin borçlarını ödeme güçlerini kaybetmesi ve kredibilitesinin azalması bağlamında üç ana başlığa ayrılmaktadır. Bunlar; karın devamlı olarak düşük ya da negatif olması, teknik likidite probleminin (vadesi gelen yükümlülüklerin karşılanamaması) yaşanması ve iflastır (Aydın, Başar ve Coşkun, 2014: 325). Finansal başarısızlığın en son noktası olan iflasın tanımı ise Türk Dil Kurumu sözlüğünde "ticari borçlarını ödeyemediği mahkeme kararı ile tespit ve ilan olunan işadamının durumu, batkı, batkınlık ve yenilgiye uğrama, değerini yitirme ya da işlevini veya görevini yapamama" olarak yapılmaktadır (www.tdk.gov.tr). İşletmenin yükümlülüklerini karş1layamaması, işletmenin her zaman iflas edeceği anlamına gelmemektedir. Dolayısıyla borçları karşılamadaki yetersizlik ve iflas kavramlarının farklı olduğunun bilinmesi önemlidir (Haber ve College, 2005: 88). İflas, işletmelerin finansal durumuna dayanılarak belirlenen bir durum olmasına rağmen, iflas kararı sadece işletmenin ya da üçüncü kişilerin isteği sonucunda yargının verdiği kararla kesinleşmektedir (Özdemir, 2011: 38).

Finansal başarısızlık/iflas bir süreç halinde başlar ve satışların azalması, nakit akışlarının düzenli olmaması, maliyetlerin yükselmesi, vadesi gelen yükümlülükleri karşılayamama, banka ve cari hesaplarda düzensizlik, müşteri ve satıcı ilişkilerinde problemler, faaliyetlerde durağanlık vb. durumlarla ortaya çıkabilmektedir (Okka, 2009: 939). Bu bağlamda finansal başarısızlığın neden olacağı olumsuz etkileri ortadan kaldırmak ya da en aza indirmek için finansal başarısızlığın önceden tahmin edilmesi büyük önem arz etmektedir. Bu bağlamda çalışmanın amacı, Türkiye'de Borsa İstanbul'da ișlem gören konaklama işletmelerinin finansal başarısızlık risklerini Beaver modeliyle ölçülmesidir. Belirlenen amaçlar doğrultusunda çalışma üç bölümden oluşmaktadır. Birinci bölümde literatürde 
yer alan benzer çalışmalara ve çalışmanın amacını belirleyen araştırma sorularına yer verilmiştir. İkinci bölümde ise araştırmanın amacı, yöntemi ve bulguları sunulmuştur. Son bölümde çalışmanın sonuç ve önerilerine yer verilmiştir.

\section{Literatür}

Konuyla ilgili yapılan literatür incelemesi sonucunda, konaklama işletmelerinin finans literatüründe kabul görmüş farklı model ve yöntemlerle finansal başarısızlık risklerinin ölçüldüğü çalışmaların kısıtlı olduğu görülmektedir. Bununla beraber konaklama işletmelerinin finansal başarısızlık risklerinin Beaver modeliyle ölçüldüğü çalışmaya tarafımızca rastlanmamıştır. Bu konu ile ilgili yapılan çalışmalar aşağıda sıralanmıştır.

Kwansa ve Parsa (1990), çalışmalarında Amerika Birleşik Devletleri'ndeki restoran alt sektöründe finansal başarısızlığı araştırmışlardır. Bu amaçla çalışmada 1970-1988 yıllarında finansal başarısızlığını açıklamış 12 restoran ile başarılı 12 restoran karşılaştırılmıştır. Çalışmanın sonucunda finansal başarısızlığın nedenlerinin finansal yönetim eksikliği, pazarlama ve satış politikalarındaki eksikliklerin olduğu sonucuna varılmıştır.

Cho (1994), çalışmasında konaklama ve restoran alt sektörlerindeki başarısızlıkların nedenlerini ve modellerin başarısızlığı önceden tahmin etme gücünü incelemiştir. Bu amaçla çalışmada restoran ve otellerin başarısızlıklarını önceden tahmin etmede kullanılan logit modeller kullanılmıştır. Çalışma sonucunda söz konusu modellerin, restoranların finansal başarısızlığını önceden tahmin etme gücü $\% 91$, otellerin finansal başarısızlıklarını tahmin etme gücü \%92 olarak saptanmıştır. Çalışmada ayrıca modellerin bir yıl öncesinde tahmin başarısının yüksek olduğu vurgulanmıştır.

Gu ve Gao (2000), çalışmalarında konaklama ve yiyecek-içecek işletmelerinin iflas riskini diskriminant analizi ile önceden tahmin etmeye çalışmışlardır. Çalışmada incelenen işletmelerin 4 tanesi otel ve motel, diğer 10 işletme ise yiyecek-içecek alt sektörüne aittir. İşletmelerin 1987-1996 yılları arasındaki finansal bilgileri kullanılarak 14 oran yardımıla diskriminant analizi uygulanmıştır. Çalışmanın sonucunda kullanılan oranların ve sektöre göre özelleştirilen diskriminant analizinin, işletmelerin başarısızlıklarını önceden tahmin etmedeki başarıs1 \% 93 bulunmuştur.
Aksu (2000), çalışmasında otel işletmelerinin başarısını etkileyen dış çevre faktörlerini incelemiştir. $\mathrm{Bu}$ çalışmada dış çevre faktörlerinin işletmeyi ekonomik yönden çok etkilediği ortaya konulmuş ve işletmenin devamlılığ1 ve başarısı için önemli bir etken olduğu saptanmıştır.

Poyraz ve Uçma (2006), ihracat sektörlerinden; tarımsal ürünler-gıda, tekstil, turizm ve ulaşım araçları sektörleri üzerinde bir çalışma gerçekleştirmişlerdir. Bahsedilen sektörlerin 1994-2001 krizlerindeki finansal başarısızlık riskleri Altman Z Skor modeliyle ölçülmüştür. Çalışmanın sonucuna göre turizm sektörü özelinde kriz ve kriz dışı dönemlere ait Altman $Z$ değerlerinde çok büyük dalgalanmaların olmadığ 1 ve bu bağlamda finansal krizlerin, turizm işletmelerinin iflas risklerini çok fazla etkilemediği sonucuna ulaşılmıştır.

Kim ve Gu (2006), yaptıkları çalışmada, Amerika Birleşik Devletleri'ndeki 32 konaklama işletmesinin finansal başarısızlıklarını önceden tahmin etmek için logit model geliştirmişlerdir. $\mathrm{Bu}$ amaçla çalışmada Amerika Birleşik Devletleri'nde bulunan konaklama işletmelerinden 16 başarısız ve 16 başarılı işletmenin 1999-2004 yılları arasındaki verileri kullanılmıştır. Çalışmanın sonucunda, oluşturulan logit modelin finansal başarısızlığı iki yıl önceden tahmin etme bașarısının \%84-\%91 arasında olduğu sonucuna ulaşılmıştır. Çalışmada ayrıca başarısız işletmelerin finansal verileri incelendiğinde nakit akışının düşük olduğu ve toplam yükümlülüklerini karşılamada yetersiz kaldığı sonucuna varılmıştır.

Türksoy (2007), konaklama işletmelerinde finansal başarısızlığa yol açabilecek faktörleri belirlemeye yönelik bir çalışma gerçekleştirmiştir. Bu amaçla hisseleri İstanbul Menkul Kıymetler Borsası'nda on beş yılı aşkın bir süredir işlem gören üç konaklama işletmesini incelemiştir. Çalışmanın sonucunda konaklama işletmelerinin finansal başarısızlık nedenleri olarak, işletmelerin var olan kapasiteden tam olarak yararlanamamas1, turizm talebi ve arzı arasında planlanan rakamların gerçekleşmemesi, nitelikli eleman bulmada yaşanan zorluk, yüksek maliyetler, müşteri istekleri doğrultusunda donanımın yenilenmesiyle artan finansal yük ve müşterilerin konaklama işletmelerini tercih farkl1lıkları olarak saptanmıştır.

Diakomihalis (2012), çalışmasında Altman Z Skor modellerini Yunanistan'daki farklı otellerin başarısız- 
lıklarını ölçmede kullanmıştır. Çalışma sonucunda Altman modellerinin Yunanistan'daki otel işletmelerinin iflas risklerinin bir yıl öncesinden tahmin edilmesinde çok başarılı olduğu sonucuna varılmıştır.

Kim ve Upneja (2013), Amerika Birleşik Devletleri'nde bulunan halka açık restoran ișletmelerinin finansal başarısızlıklarını öngörebilmek için restoranların 1988-2010 yıllarına ait finansal verilerini kullanarak Karar Ağaçları ve Ad Boosted Karar Ağacı modellerini kullanmışlardır. Çalışmanın sonucunda Ad Boosted Karar Ağacı modelinin başarısızlığı önceden tahmin etmede daha başarılı olduğu sonucuna ulaşılmıştır. Ayrıca finansal başarısızlık yaşayan işletmelerin borçlanma oranlarının fazla olduğu, düşük kar marjına sahip oldukları ve verimlilik düzeyinin çok düşük olduğu vurgulanmıştır.

Cihangir ve Kara (2014), çalışmalarında Türkiye'nin Kapadokya destinasyonunda bulunan konaklama işletmelerinin finansal başarısızlıklarına neden olabilecek etkenleri incelemişlerdir. Çalışmanın sonucunda Kapadokya'daki konaklama işletmelerinde finansal başarısızlık yaşanmadığı saptanmıştır. Pacheco (2015), çalışmasında Portekiz'de bulunan küçük ve orta ölçekli konaklama işletmelerinin finansal başarısızlıklarını ölçmüştür. Çalışmanın sonucunda kullanılan modelin finansal başarısızlığı tahmin etmede zayıf olduğu belirlenerek bunun nedeninin ise işletmelerin doğru veri paylaşımında bulunmama ihtimali ve modelin konaklama işletmelerine çok uygun olmadığ gulanmıştır.

Mizdrakovic, Knezevic ve Stanic (2015), çalışmalarında Sırbistan'da bulunan konaklama işletmelerinin borçluluk düzeylerini finansal başarısızlığı önceden tahmin etmede kullanılan modellerden yararlanarak incelemişlerdir. İşletmelere, 2008-2012 yıllarına ait finansal verileri kullanarak Altman Z' Skoru, Altman Z Skoru', M Skor, Kralicek's Df Skoru ve konaklama sektörü için oluşturulan Z-Skor modelleri kullanılmıştır. Çalışmanın sonucunda işletmelerin 2010 ve 2011 yıllarında finansal anlamda başarısızlık yaşadığı sonucuna varılmıştır.

Bua, Sestayo ve Gonzalez (2016), çalışmalarında İspanya'da bulunan konaklama işletmelerinin finansal başarılarını probit ve logit modellerini kullanarak ölçmüşlerdir. Örneklem olarak seçilen küçük ve orta ölçekli 682 işletmenin 2008-2011 yıllarına ait finansal verileri kullanılmıştır. Çalışmanın sonucunda kullanılan modellerin finansal başarısızlığı ölçmede başarılı olduğu fakat sektöre özel modellerin geliştirilmesi gerektiği vurgulanmıştır.

Mammadli ve Helhel (2017), çalışmalarında "marka yetenek geliștiriciler" olarak adlandırılan ve "Fortune: 100 Best Companies to Work for 2017" listesinde yer alan turizm işletmelerinin iflas risklerini Altman Z' Skor modeliyle ölçmüşlerdir. Analiz sonucunda The Cheesecake Factory restoranının iflas riskinin bulunmadığı diğer iki işletmeye göre finansal durumunun daha iyi durumda olduğu; Hyatt Otel işletmesinin finansal başarıda belirsizlik gözlemlendiği ve Marriot International işletmesinin iflas riskinin yüksek olduğu sonucuna varılmıştır.

Jawabreh, Rawashdeh ve Senjelawi (2017), çalışmalarında Ürdün'de bulunan konaklama işletmelerinin finansal başarısızlıklarını Altman Z Skoru yardımıyla ölçmüşlerdir. $\mathrm{Bu}$ amaçla Amman borsasında bulunan 13 konaklama işletmesinin 2008-2009 yıllarına ait verilerini Altman Z Skoruna tabi tutmuşlardır. Çalışmanın sonucunda işletmelerin finansal başarısızlıklarının bir y1l öncesinden tahmin edilebileceği sonucuna varılmiştır.

Karaca ve Özen (2017), yaptıkları çalışmada Türkiye turizm sektöründeki son gelişmelerin, Borsa İstanbul'da bulunan turizm işletmelerinin finansal başarısızlıkları üzerindeki etkisini incelemişlerdir. İşletmelerin finansal tablolarından yararlanarak 2009-2016 yı1ları arasındaki verileri yardımıyla Altman Z Skoru ile iflas riski taşıyıp taşımadığı ölçülmüştür. Aynı zamanda işletmelerin hisse senetlerinin döviz fiyatları hesaplanan Z Skoru ile karşılaştırılıp aradaki fiyat değişiminin ne kadar olduğu ölçülmüştür. Çalışmanın sonucunda 2015-2016 yıllarında yaşanan Türkiye ve Rusya arasındaki uçak krizinin neden olduğu sorunlar turizm işletmelerinin iflas riskini yükselttiği saptanmıştır. Ayrıca bu dönem için işletmelerin hisse senedi fiyatlarında önemli bir değişiklik olmadığı gözlemlenmiștir. Regresyon analizi sonucunda ise iflas olasıl1 $\breve{g}_{1-}$ nın fiyatlar üzerindeki etkisinin anlamlı olmadığı saptanmıștır.

\section{Yöntem}

Bu çalışmanın amacı, Türkiye'de Borsa İstanbul'da işlem gören konaklama işletmelerinin finansal başarı- 
sızlık risklerini Beaver modeliyle ölçmek ve yıllar arasında bir farklılık olup olmadığını ortaya koymaktır. Çalışmada belirlenen amaçlar doğrultusunda ikincil veriler kullanılarak araştırmaya dahil edilen ve Borsa İstanbul'da işlem gören 11 konaklama işletmesinin 2012-2017 yıllarına ait finansal tabloları incelenmiş ve Beaver modeli uygulanmıştır. Bu doğrultuda çalışma ile ilgili araştırma soruları aşağıdaki gibidir;

- Türkiye'de halka açık konaklama işletmelerinin Beaver Modeline göre finansal başarısızlık riski nedir?

- Türkiye'de halka açık konaklama işletmelerinin Beaver Modeline göre finansal başarısızlığını en çok etkileyen oranlar nelerdir?

Analizde kullanılan model, ilk defa Beaver (1966) çalışmasında geliştirilmiştir. Bu çalışmada başarısız$1 \mathrm{k}$, işletmelerin finansal yükümlülüklerini yerine getirmede yetersiz kalması olarak tanımlanmıştır. Beaver (1966), araştırmasında 1954-1964 dönemlerinde başarısızlığa uğramış 79 işletme seçmiştir. Bu işletmeler Moody's tarafından hazırlanan başarısız işletme listesinden ve Dun \& Bradstreet tarafindan hazırlanan listelerden seçilmiştir. Ardından işletmelerin varlık büyüklüklerine ve endüstriyel alanlarına göre Moody's tarafından hazırlanmış 12.000 adet başarılı işletmenin bulunduğu listeden 79 başarılı işletme seçilmiștir. Bu liste oluşturulurken işletmeler, endüstri alanlarına ve büyüklüklerine göre sıraya konulmuş ve gruplandırılmiştır.

Beaver, incelediği oranları literatürde en çok tercih edilme ve kullanım amaçlarını göz önünde bulundurarak 6 başlıkta toplamıştır. Daha sonra başarısız işletmelerin finansal başarısızlıklarının kendini göstermeye başladığı yıldan itibaren geriye dönük olarak 5 seneyi kapsayan ve finansal tablolardan elde edilen verilerle başarılı işletmelerin finansal tablo verilerini karşılaştırmıştır. Beaver, oluşturduğu modelde aşağıdaki oranları kullanmıştır (Sevil, Başar ve Mehmet, 2013);

- Nakit Akış/Toplam Borçlar

- Net Kar/Toplam Varlıklar

- Toplam Borçlar/Toplam Varlıklar

- Dönen Varlıklar/Kısa Vadeli Yabancı Kaynaklar

- Net Çalışma Sermayesi/Faaliyet Giderleri

- Net Çalışma Sermayesi/Toplam Varlıklar

Beaver'ın araştırmasında, finansal oranların değerinin bașarılı ișletmelerde bașarısız ișletmelere nazaran daha yüksek bulunduğu göze çarpmıştır. Başarısız bulunan işletme oranlarının, başarısız olarak nitelendirilen döneme doğru gidildikçe hızlı bir şekilde azaldığı saptanmıştır (Berk, 1998: 470). Beaver, en son olarak işletmelerin nihai olarak nakit akış1/toplam borç oranının işletmelerin finansal başarısızlıklarını önceden tahminlemede başarılı sonuçlar sergilediğini ortaya koymuştur (Aktaş, 1991; Sevil, Başar ve Mehmet, 2013).

Çalışmanın evreni; Türkiye'de faaliyet gösteren halka açık 11 konaklama işletmesidir. Çalışmanın amac1 doğrultusunda işletmelerin verileri Thomson Reuters Eikon veri tabanından ve Kamuyu Aydınlatma Platformu'nda (www.kap.org.tr) yer alan finansal tablolardan y1llık veriler halinde temin edilmiştir. Çalışmaya dâhil edilen işletmelerin her biri için 2012-2017 yılları arasındaki Beaver modeline ait oranlar hesaplanmıştır. Bu bağlamda 11 işletmenin altı yıl için ayrı ayrı 6 oranı hesaplanmış ve toplam olarak 396 gözlem gerçekleştirilmiştir. Çalışmada analiz kapsamındaki konaklama işletmeleri aşağıdaki tabloda sunulmaktadir.

Tablo 1. Analiz kapsamındaki Türkiye'de faaliyet gösteren halka açık konaklama işletmeleri

\begin{tabular}{|c|c|}
\hline $\begin{array}{r}\text { Borsa } \\
\text { (Ülke) } \\
\end{array}$ & Halka açık konaklama işletmeleri \\
\hline $\begin{array}{l}\text { Borsa İs- } \\
\text { tanbul } \\
\text { (Türkiye) }\end{array}$ & $\begin{array}{l}\text { Altınyunus Çeşme Turistik Tesisler A.Ş. } \\
\text { (AYCES)*, } \\
\text { Avrasya Petrol ve Turistik Tesisler Yatı- } \\
\text { rımlar A.Ş. (AVTUR)*, } \\
\text { Kuştur Kuşadası Turizm Endüstrisi A.Ş. } \\
\text { (KSTUR)*, } \\
\text { Marmaris Altınyunus Turistik Tesisler } \\
\text { A.Ş. (MAALT)*, } \\
\text { Martı Otel İşletmeleri A.Ş. (MARTI)*, } \\
\text { Merit Turizm Yatırım ve İşletme A.Ş. } \\
\text { (MERIT)*, } \\
\text { Metemtur Otelcilik ve Turizm İşletmeleri } \\
\text { A.Ş. (METUR)*, } \\
\text { Petrokent Turizm A.Ş. (PKENT)*, } \\
\text { Tek-Art İnşaat Ticaret Turizm Sanayi ve } \\
\text { Yatırımlar A.Ş. (TEKTU)*, } \\
\text { Ulaşlar Turizm Yatırımları ve Dayanıklı } \\
\text { Tüketim Malları Ticaret Pazarlama A.Ş. } \\
\text { (ULAS)*, } \\
\text { Utopya Turizm İnşaat İşletmecilik Ticaret } \\
\text { A.Ş. (UTPYA)*. }\end{array}$ \\
\hline
\end{tabular}

*= Tabloda yıldızla işaretlenen turizm işletmeleri sermaye piyasasında işlem gören halka açık işletmeler olduklarından dolayı, araştırmanın ilerleyen kısımlarında Sermaye Piyasası Kanunu uyarınca herhangi bir finansal spekülasyona neden olmamak için harflerle kodlanarak sunulmaktadır. 


\section{Bulgular}

Çalışmanın amacı doğrultusunda bu bölümde Beaver modelinde elde edilen bulgulara göre, Borsa İstanbul'da işlem gören halka açık konaklama işletmelerinin sonuçları sunulmakta ve elde edilen bulgular yorumlanmaktadır. Aşağıdaki tablo 2'de Borsa İstanbul'da işlem gören konaklama işletmelerinin 20122017 yılları arasındaki Beaver modelinde hesaplanan oranları sunulmaktadır. Tabloda analize dahil edilen her bir konaklama işletmesinin isimleri harf kodlamalarıyla belirtilmektedir. Tabloda ayrica her bir işletmenin analiz süreci içerisindeki Beaver oranlarının yıllar bağlamında ortalaması sunulmaktadır. Tablo 2 . incelendiğinde Beaver'ın oranlarından ilki olan Nakit Akış/Toplam Borçlar oranı, işletmenin bir döneminde faaliyetlerinden elde ettiği nakitleriyle toplam borçlarının mukayese ederek, yükümlülükleriyle orantılı nakit kazanç sağlayıp sağlamadığını ifade etmektedir. Oran ne kadar yüksek olursa işletmelerin uzun vadeli borç sağlamaları o denli kolaylaşmaktadır. Söz konusu oranın 0.20 ya da daha yüksek olması yeterli görülmektedir (Schmidgall vd., 2003'den aktaran; Met, 2013:124).

A işletmesinin Nakit Akış/Toplam Borçlar oranına ait değerleri 2016 yılı haricinde istenilen oranın üzerindeyken, 2016 y1lında optimum düzeyin oldukça altında kalarak negatif gerçekleşmiştir. B işletmesinin değerleri 2015 yılına kadar standardın altında gerçekleşmişken, 2015 ve 2016 y1lında optimum düzeyin oldukça üstünde gerçekleşmiştir. 2015 yılında negatif değere sahip olan işletme, 2017 yılında borcu olmadığ 1 için oran hesaplanamamıştır. C işletmesinin ise tüm yıllar bağlamında istenilen düzeyin oldukça üstünde değerlere sahip olduğu görülmektedir. D işletmesinin Nakit Akış/Toplam Borçlar oranı, yalnızca 2013 yılında negatif bir değer alarak optimum düzeyin oldukça altında gerçekleşirken diğer tüm yıllarda optimal düzeyin üzerinde gerçekleşmiştir. İşletmenin 2017 yılına ait borcu olmadığından bu oran 2017 y1lı için hesaplanamamıştır. E işletmesinin Nakit Akış/Toplam Borçlar oranı değerlerinin analize dahil edilen tüm yıllar itibariyle istenilen düzeyin oldukça altında olduğu ve 2012 ve 2017 yıllarında negatif gerçekleştiği görülmektedir. F işletmesinin Nakit Akış/Toplam Borçlar oranı değerlerinin dalgalı bir seyir izlediği görülmektedir. İşletmenin değerleri 2012, 2013, 2016 ve 2017 y1llarında istenilen düzeyin altındayken, 2014 ve 2015 yıllarında oldukça yüksek gerçekleştiği gözlemlenmiştir. G işletmesinin tüm yıllara ait Nakit Akış/Toplam Borçlar oran değerleri incelendiğinde, bu oranın tüm yıllar bağlamında istenilen optimum düzeyin üzerinde seyrettiği ancak 2017 yılında optimum düzeyin oldukça altında negatif değere sahip olduğu görülmektedir. $\mathrm{H}$ işletmesinin Nakit Akış/Toplam Borçlar oranı değerleri incelendiğinde, bu oranın 2012, 2014, 2016 ve 2017 yıllarında standardın altında gerçekleşirken, 2013 ve 2015 yıllarında standardın üstünde gerçekleştiği gözlemlenmiştir. I işletmesinin Nakit Akış/Toplam Borçlar oranı değerleri incelendiğinde, 2015 yılına kadar standardın üstünde değerler söz konusuyken 2015, 2016 ve 2017 yıllarında standardın oldukça altında gerçekleştiği görülmektedir. $\mathrm{J}$ işletmesinin Nakit Akış/Toplam Borçlar oranı değerleri incelendiğinde, 2012 yılında optimum düzeyin üstünde olan oranın 2013, 2014, 2015, 2016 ve 2017 yıllarında optimum düzeyin altında gerçekleştiği saptanmıştır. Özellikle işletmenin 2017 yılına ait değerlerinin optimum düzeyden oldukça düşük, negatif değerde olduğu görülmektedir. K işletmesinin Nakit Akış/Toplam Borçlar oranı değerleri incelendiğinde, oran değerlerinin 2012 ve 2014 yıllarında istenilen düzeyin üstünde gerçekleştiğ $i$ buna karşın 2013, 2015, 2016 ve 2017 yıllarında istenilen düzeyin altında gerçekleştiği görülmektedir.

Beaver'ın oranlarından ikincisi olan Net Kar/Toplam Varlıklar (Aktif Karlılık) oranı, ağırlama işletmesi varlıklarının genel karlılığını ifade etmektedir. Bu oran işletmenin gerçekleştirdiği her 100 TL'lik aktif yat1rımı karşılığında kaç TL net kar sağladığını belirtmektedir. Karşıllaştırma kıstaslarına göre düşük olduğu gözlemlenen oran aşırı varlık yatırımının ya da yetersiz karların göstergesi olabilmektedir (Met, 2013: 98). A işletmesi açısından aktif karlılık oranının 2012 yılında pozitif gerçekleştiği, buna karşın işletmenin sonraki tüm yıllarında oranın negatif gerçekleştiği saptanmıştır. B işletmesinin aktif karlılık oranları incelendiğinde, 2012, 2013 ve 2017 yıllarında söz konusu oranın negatif değerlere sahipken 2014, 2015 ve 2016 yıllarında pozitif değerlere sahip olduğu gözlemlenmiştir. $\mathrm{C}$ işletmesinin aktif karlılık oran değerleri incelendiğinde söz konusu oranın tüm yıllar itibariyle pozitif değer aldıkları saptanmıştır. D ve F işletmelerinin aktif karlılık oran değerlerinin analize dahil edilen tüm yıllarda pozitif gerçekleştiği görülmektedir. E işletmesinin aktif karlılık oranlarının ise tüm yıllar bağlamında negatif gerçekleştiği saptanmıştır. G işletmesinin aktif karlılık oran değerlerinin ise y1llara göre dalgalanma gösterdiği saptanmıştır. 
Tablo 2. Borsa İstanbul'da işlem gören konaklama işletmelerinin Beaver modeli oranları

\begin{tabular}{|c|c|c|c|c|c|c|c|c|}
\hline İșl. & Beaver Modeli Oranları & 2017 & 2016 & 2015 & 2014 & 2013 & 2012 & Ort. \\
\hline \multirow{6}{*}{ 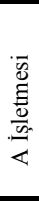 } & Nakit Akış1 / Toplam Borçlar & 0,00 & $(0,01)$ & 0,32 & 0,25 & 0,77 & 0,45 & 0,30 \\
\hline & Net Kar / Toplam Varlıklar & $(0,03)$ & $(0,05)$ & $(0,01)$ & $(0,01)$ & $(0,01)$ & 0,01 & $(0,02)$ \\
\hline & Toplam Borçlar / Toplam Varliklar & 0,10 & 0,09 & 0,05 & 0,06 & 0,06 & 0,06 & 0,07 \\
\hline & N.C.S. / Toplam Var. & $(0,06)$ & $(0,03)$ & $(0,01)$ & $(0,07)$ & $(0,05)$ & $(0,02)$ & $(0,04)$ \\
\hline & Dönen Varlıklar / K.V.Y.K. & 0,23 & 0,40 & 0,64 & 0,25 & 0,45 & 0,62 & 0,43 \\
\hline & N.Ç.S. / Faaliyet Gider. & $(0,37)$ & $(0,19)$ & $(0,06)$ & $(0,34)$ & $(0,22)$ & $(0,13)$ & $(0,22)$ \\
\hline \multirow{6}{*}{ 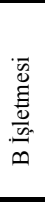 } & Nakit Akıș1 / Toplam Borçlar & - & 0,45 & 2,63 & $(3,46)$ & 0,05 & 0,06 & $(0,05)$ \\
\hline & Net Kar / Toplam Varlıklar & $(0,10)$ & 0,09 & 0,02 & 0,09 & $(0,00)$ & $(0,03)$ & 0,01 \\
\hline & Toplam Borçlar / Toplam Varlıklar & 0,00 & 0,18 & 0,12 & 0,08 & 0,10 & 0,08 & 0,09 \\
\hline & N.Ç.S. / Toplam Var. & $(0,01)$ & $(0,09)$ & $(0,02)$ & 0,33 & $(0,03)$ & $(0,02)$ & 0,03 \\
\hline & Dönen Varlıklar / K.V.Y.K. & 0,69 & 0,30 & 0,80 & 10,69 & 0,45 & 0,51 & 2,24 \\
\hline & N.Ç.S. / Faaliyet Gider. & $(0,08)$ & $(10,35)$ & $(1,77)$ & 55,46 & $(2,83)$ & $(1,29)$ & 6,52 \\
\hline \multirow{6}{*}{ 跑 } & Nakit Akışı / Toplam Borçlar & 1,47 & 1,19 & 0,68 & 1,10 & 1,96 & 2,66 & 1,51 \\
\hline & Net Kar / Toplam Varlıklar & 0,13 & 0,04 & 0,10 & 0,15 & 0,18 & 0,11 & 0,12 \\
\hline & Toplam Borçlar / Toplam Varlıklar & 0,06 & 0,05 & 0,18 & 0,16 & 0,10 & 0,07 & 0,10 \\
\hline & N.C.S. / Toplam Var. & 0,00 & 0,25 & 0,23 & 0,16 & 0,24 & 0,34 & 0,20 \\
\hline & Dönen Varlıklar / K.V.Y.K. & 6,51 & 6,84 & 2,34 & 2,02 & 3,70 & 6,64 & 4,68 \\
\hline & N.Ç.S. / Faaliyet Gider. & 0,00 & 9,04 & 13,01 & 6,01 & 9,15 & 9,25 & 7,74 \\
\hline \multirow{6}{*}{ 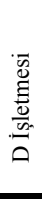 } & Nakit Akıș1 / Toplam Borçlar & - & 0,90 & 2,05 & 3,13 & $(2,72)$ & 0,83 & 0,84 \\
\hline & Net Kar / Toplam Varlıklar & 0,04 & 0,02 & 0,06 & 0,05 & 0,02 & 0,06 & 0,04 \\
\hline & Toplam Borçlar / Toplam Varlıklar & 0,00 & 0,12 & 0,04 & 0,02 & 0,02 & 0,10 & 0,05 \\
\hline & N.C.S. / Toplam Var. & 0,32 & 0,29 & 0,34 & 0,27 & 0,20 & 0,23 & 0,28 \\
\hline & Dönen Varlıklar / K.V.Y.K. & 3,19 & 3,49 & 10,18 & 17,58 & 12,88 & 10,54 & 9,64 \\
\hline & N.Ç.S. / Faaliyet Gider. & 3,57 & 3,37 & 4,15 & 4,01 & 1,25 & 1,26 & 2,94 \\
\hline \multirow{6}{*}{ 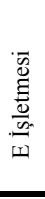 } & Nakit Akıș1 / Toplam Borçlar & $(0,02)$ & 0,15 & 0,09 & 0,09 & 0,14 & $(0,16)$ & 0,05 \\
\hline & Net Kar / Toplam Varlıklar & $(0,02)$ & $(0,12)$ & $(0,05)$ & $(0,09)$ & $(0,04)$ & $(0,03)$ & $(0,06)$ \\
\hline & Toplam Borçlar / Toplam Varlıklar & 0,70 & 0,46 & 0,35 & 0,60 & 0,46 & 0,34 & 0,49 \\
\hline & N.C.S. / Toplam Var. & $(0,19)$ & $(0,19)$ & $(0,20)$ & $(0,17)$ & $(0,12)$ & $(0,10)$ & $(0,16)$ \\
\hline & Dönen Varlıklar / K.V.Y.K. & 0,25 & 0,26 & 0,35 & 0,56 & 0,68 & 0,72 & 0,47 \\
\hline & N.Ç.S. / Faaliyet Gider. & $(2,29)$ & $(1,44)$ & $(2,47)$ & $(0,82)$ & $(0,58)$ & $(0,43)$ & $(1,34)$ \\
\hline \multirow{6}{*}{ 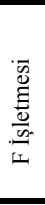 } & Nakit Akıșı / Toplam Borçlar & 0,00 & $(1,72)$ & 2,07 & 4,72 & $(0,00)$ & 0,00 & 0,85 \\
\hline & Net Kar / Toplam Varlıklar & 0,21 & 0,17 & 0,16 & 0,21 & 0,34 & 0,06 & 0,19 \\
\hline & Toplam Borçlar / Toplam Varlıklar & 0,12 & 0,08 & 0,09 & 0,10 & 0,14 & 0,08 & 0,10 \\
\hline & N.C.S. / Toplam Var. & 0,30 & 0,20 & 0,24 & 0,08 & 0,43 & 0,16 & 0,24 \\
\hline & Dönen Varlıklar / K.V.Y.K. & 3,60 & 3,46 & 4,17 & 1,84 & 4,11 & 3,33 & 3,42 \\
\hline & N.C..S. / Faaliyet Gider. & 1,28 & 0,71 & 0,95 & 0,38 & 2,08 & 0,93 & 1,06 \\
\hline \multirow{6}{*}{ 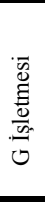 } & Nakit Akışı / Toplam Borçlar & $(0,98)$ & 17,59 & 0,30 & 0,20 & 0,33 & 0,38 & 2,97 \\
\hline & Net Kar / Toplam Varlıklar & $(0,05)$ & 0,45 & 0,31 & $(0,23)$ & $(0,26)$ & 0,22 & 0,07 \\
\hline & Toplam Borçlar / Toplam Varlıklar & 0,58 & 0,12 & 0,83 & 1,29 & 1,05 & 0,82 & 0,78 \\
\hline & N.C.S. / Toplam Var. & 0,17 & 0,70 & 0,84 & 0,43 & 0,47 & 0,56 & 0,53 \\
\hline & Dönen Varlıklar / K.V.Y.K. & 2,32 & 6,86 & 10,23 & 2,52 & 2,83 & 3,58 & 4,72 \\
\hline & N.Ç.S. / Faaliyet Gider. & 1,64 & 0,34 & 3,03 & 6,72 & 4,77 & 2,93 & 3,24 \\
\hline \multirow{6}{*}{ 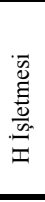 } & Nakit Akıșı / Toplam Borçlar & 0,09 & $(0,34)$ & 0,45 & 0,03 & 0,45 & $(0,09)$ & 0,10 \\
\hline & Net Kar / Toplam Varliklar & 0,05 & $(0,26)$ & 0,02 & $(0,04)$ & 0,08 & $(0,12)$ & $(0,05)$ \\
\hline & Toplam Borçlar / Toplam Varlıklar & 0,44 & 0,52 & 0,32 & 0,24 & 0,30 & 0,33 & 0,36 \\
\hline & $\begin{array}{l}\text { N.C.S. / Toplam Var. } \\
\end{array}$ & $(0,40)$ & $(0,50)$ & $(0,23)$ & $(0,26)$ & $(0,12)$ & $(0,23)$ & $(0,29)$ \\
\hline & Dönen Varlıklar / K.V.Y.K. & 0,42 & 0,32 & 0,56 & 0,47 & 0,72 & 0,51 & 0,50 \\
\hline & N.Ç.S. / Faaliyet Gider. & $(0,54)$ & $(0,66)$ & $(0,30)$ & $(0,33)$ & $(0,16)$ & $(0,26)$ & $(0,38)$ \\
\hline \multirow{6}{*}{ 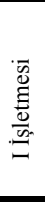 } & Nakit Akıșı / Toplam Borçlar & 0,01 & $(0,04)$ & $(0,01)$ & 0,25 & 1,08 & 0,63 & 0,32 \\
\hline & Net Kar / Toplam Varlıklar & 0,02 & $(0,05)$ & 0,01 & 0,01 & 0,01 & 0,01 & 0,00 \\
\hline & Toplam Borçlar / Toplam Varlıklar & 0,34 & 0,41 & 0,31 & 0,07 & 0,03 & 0,01 & 0,20 \\
\hline & N.C..S. / Toplam Var. & 0,04 & 0,15 & 0,31 & 0,07 & 0,09 & 0,10 & 0,13 \\
\hline & Dönen Varlıklar / K.V.Y.K. & 1,16 & 1,88 & 4,36 & 1,42 & 2,09 & 2,70 & 2,27 \\
\hline & N.C.S. / Faaliyet Gider. & 0,90 & 4,29 & 4,07 & 1,14 & 0,99 & 1,63 & 2,17 \\
\hline \multirow{6}{*}{ 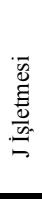 } & Nakit Akışı / Toplam Borçlar & $(2,35)$ & $(0,29)$ & 0,14 & $(0,00)$ & $(0,21)$ & 0,43 & $(0,38)$ \\
\hline & Net Kar / Toplam Varlıklar & 0,46 & $(0,13)$ & $(0,15)$ & $(0,03)$ & $(0,08)$ & $(0,02)$ & 0,01 \\
\hline & Toplam Borçlar / Toplam Varlıklar & 0,22 & 0,45 & 0,36 & 0,51 & 0,35 & 0,07 & 0,33 \\
\hline & N.Ç.S. / Toplam Var. & 0,21 & $(0,28)$ & 0,21 & 0,00 & $(0,03)$ & 0,20 & 0,05 \\
\hline & Dönen Varlıklar / K.V.Y.K. & 2,66 & 0,39 & 1,72 & 1,01 & 0,77 & 5,76 & 2,05 \\
\hline & N.C.S. / Faaliyet Gider. & 14,69 & $(7,61)$ & 1,51 & 0,02 & $(0,15)$ & 1,09 & 1,59 \\
\hline \multirow{6}{*}{ 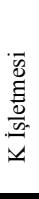 } & Nakit Akıș1 / Toplam Borçlar & 0,00 & 0,12 & $(0,28)$ & 0,20 & 0,10 & 0,22 & 0,06 \\
\hline & Net Kar / Toplam Varlıklar & $(0,08)$ & $(0,14)$ & $(0,10)$ & $(0,01)$ & $(0,11)$ & 0,03 & $(0,07)$ \\
\hline & Toplam Borçlar / Toplam Varlıklar & 0,45 & 0,43 & 0,36 & 0,29 & 0,32 & 0,28 & 0,36 \\
\hline & N.C..S. / Toplam Var. & $(0,16)$ & $(0,15)$ & $(0,08)$ & $(0,19)$ & $(0,14)$ & $(0,03)$ & $(0,13)$ \\
\hline & Dönen Varlıklar / K.V.Y.K. & 0,46 & 0,49 & 0,66 & 0,37 & 0,50 & 0,85 & 0,56 \\
\hline & N.C.S. / Faaliyet Gider. & $(1,02)$ & $(1,09)$ & $(0,48)$ & $(1,05)$ & $(0,59)$ & $(0,21)$ & $(0,74)$ \\
\hline Orta & & 0,65 & 0,64 & 1,08 & 1,83 & 0,74 & 0,90 & \\
\hline
\end{tabular}


İşletmenin değerlerinin 2013, 2014 ve 2017 yıllarında negatif gerçekleştiği, buna karşın 2012, 2015 ve 2016 y1llarında pozitif gerçekleştiği saptanmıştır. H işletmesinin aktif karlılık oranlarının 2012, 2014 ve 2016 y1llarında negatif 2013, 2015 ve 2017 yıllarında ise pozitif gerçekleştiği görülmektedir. I işletmesinin yıllar bağlamında aktif karlılık oran değerleri incelendiğinde söz konusu oranın 2016 yılı dışındaki yıllarda pozitif gerçekleştiği görülmektedir. J işletmesinin aktif karlı1ık oranlarının ise 2017 yılı haricinde tüm yıllarda negatif gerçekleştiği görülmektedir. K işletmesinin aktif karlılık oran değerleri incelendiğinde ise işletmenin 2012 yılı dışındaki tüm yıllarında negatif değerlere sahip olduğu görülmektedir.

Beaver'ın oranlarından üçüncüsü olan Toplam Borçlar/Toplam Varlıklar (Finansal Kaldıraç) oranı, işletmelerin varlıklarının yüzde kaçını yabancı kaynaklarla finanse ettiklerini ifade etmektedir. Bu oranın kredi verenler açısından düşük olması istenirken işletme yöneticileri tarafindan kaldıraç etkisinden yararlanarak karlılığ 1 arttırmak amaciyla yüksek olması istenebilmektedir. Gelişmiş ülkelerde söz konusu oranın \%50'nin üstüne çıkılması istenen bir durum değildir (Elmas, 2015: 199). A işletmesinin finansal kaldıraç oranları tüm yıllar itibariyle pozitif bir tutum sergilemektedir. İşletme söz konusu varlıklarının çok düşük bir kısmını yabancı kaynaklarla finanse etmektedir. B işletmesinin ise sahip olduğu varlıkları yabancı kaynaklarla finanse etme durumunun yıllar itibariyle artış eğilimi gösterdiği belirlenmiştir. Ayrıca B işletmesinin 2017 yılında borç kullanmadığı görülmektedir. C işletmesinin 2012-2016 y1lları arasında finansal kaldıraç oranlarının yükselme eğilimi gösterdiği buna karşın 2017 y1lında bu eğilimin düşme yönünde olduğu saptanmıştır. D işletmesinin finansal kaldıraç değerlerinin 2012 y1lından 2015 y1lına kadar düşüş, 2016 yılında artış gösterdiği ancak 2017 y1lında tekrar düşüş gösterdiği görülmektedir. Ayrıca D işletmesinin 2017 yılında borç kullanmadığı görülmektedir. E işletmesinin finansal kaldıraç oranlarının ise oldukça yüksek olduğu hatta 2014 ve 2017 yıllarında optimal düzeyin üstüne çıktığı saptanmıştır. Bu bağlamda söz konusu işletmenin durgunluk dönemlerinde yükümlülüklerini yerine getirme hususunda finansal açıdan sıkıntıya düşeceği söylenebilir. F işletmesinin finansal kaldıraç oranları incelendiğinde, tüm yıllar bağlamında genel olarak yabancı kaynak kullanımının azalma eğilimi gösterdiği görülmektedir. G işletmesinin finansal kaldıraç oranlarının ise 2016 y1lına kadar optimum düzeyin oldukça üstünde gerçekleştiği buna karşın 2016 yılında bu oranın oldukça düştüğü ancak 2017 yılında tekrar optimum düzeyin üzerine çıktığı görülmektedir. H işletmesinin değerleri incelendiğinde, y1llar itibariyle dalgalı bir seyir izlediği görülmüştür. 2016 y1lına kadar tüm yıllarda ve 2017 y1lında optimal düzeyin altında iken 2016 yılında optimal düzeyin üzerine çıktığı görülmektedir. I işletmesinin değerlerinin yıllar itibariyle artış gösterdiği ancak optimal düzeyin altında olduğu görülmektedir. $\mathrm{J}$ işletmesinin değerleri incelendiğinde, tüm yıllar itibariyle artış eğilimi gösterdiği ve 2014 y1lında ise standart değerin üzerine çıktığı saptanmıştır. $\mathrm{K}$ işletmesinin finansal kaldıraç oranları değerlendirildiğinde tüm yıllar bağlamında artış gösterdiği ancak optimum düzeyin altında gerçekleştiği görülmektedir.

Beaver'ın oranlarından dördüncüsü olan Net Çalışma Sermayesi/Toplam Varlıklar oranı incelendiğinde, $\mathrm{A}, \mathrm{E}, \mathrm{H}$ ve $\mathrm{K}$ işletmelerinin faaliyetlerine devam etmek için ihtiyaç duyduğu net işletme sermaye tutarlarının aktifler içindeki yüzdesinin tüm yıllarda negatif olarak gerçekleştiği gözlemlenmiştir. Bu durum işletmelerin duran varlıklarının bir kısmını da kısa vadeli yabancı kaynaklarla finanse ettiğini göstermektedir. C, D, F, G ve I işletmelerinin ise analize dahil olan tüm yıllarda net çalışma sermayesi/toplam varlıklar oranın pozitif olduğu saptanmıştır. $\mathrm{B}$ ve $\mathrm{J}$ işletmelerinin ise net çalışma sermayesi/toplam varlıklar oranlarının analiz döneminde dalgalı bir seyir izlediği görülmektedir.

Beaver'ın oranlarından beşincisi olan Dönen Varl1klar/K1sa Vadeli Yabancı Kaynaklar oranı (Cari Oran), bir işletmenin sahip olduğu dönen varlıklarla kısa vadeli borçlarını karşılamadaki gücünü ölçmektedir. Oranın imalat işletmeleri açısından 2 olması beklenirken ağırlama işletmelerinde alacaklar ve stokların görece az olması ve paraya çevrilme hızlarının fazla olmas1 sebebiyle en az 1 olmas1 yeterli görülmektedir (Met, 2013: 70). A işletmesinin cari oran değerlerine bakıldığında, işletmenin tüm yıllar genelinde kısa vadeli borçlarını dönen varlıklarıyla karşılayamadıkları söylenebilir. B işletmesinin değerlerine bakıldığında, 2014 haricindeki tüm yıllarda optimum düzeyin altında kaldığını ancak 2014 yılında ise söz konusu oran standardının oldukça üzerinde olduğu saptanmıştır. Dolayısıyla işletmenin o yıl için sahip olduğu varlıkları atıl 
tuttuğu gözlemlenmektedir. C işletmesinin cari oranları incelendiğinde, işletmenin tüm yıllar bağlamında değerlerinin optimum düzeyin üzerinde gerçekleştiği ve varlıklarını atıl durumda tuttuğu görülmektedir. D işletmesinin cari oranlarının ise analiz döneminde standardın oldukça üstünde gerçekleştiği görülmektedir. $\mathrm{Bu}$ bağlamda işletmenin fonlarını atıl tuttuğu ve kaynaklarını etkin kullanmadığı söylenebilir. E işletmesinin değerleri incelendiğinde, tüm yıllar için optimum düzeyin altında kaldığı ve sahip olduğu varlıklarla kısa vadeli yabancı kaynaklarını karşılama hususunda yetersiz olduğu görülmektedir. F işletmesinin 2012-2017 yılları arasındaki değerlerine göre işletmenin oranlarının standardının üstünde seyir izlediği görülmektedir. $\mathrm{G}$ işletmesinin cari oranlarına göre işletmenin tüm yıllarda optimum düzeyin üzerinde olduğu ve kaynaklarını verimli kullanmadığı söylenebilir. $\mathrm{H}$ işletmesinin cari oranları incelendiğinde, tüm yıllar için standardın altında olduğu saptanmıştır. İşletmenin vadesi gelen kısa vadeli yükümlülüklerini yerine getirmede sıkıntıya düşeceği söylenebilmektedir. I işletmesinin değerleri incelendiğinde, tüm yıllar bağlamında optimum düzeyin üzerinde olduğu ancak 2016 ve 2017 yıllarında cari oran değerinin düştüğü görülmektedir. J işletmesinin cari oranlarına göre 2012, 2014, 2015 ve 2017 y1llarında optimum düzeyin üzerindeyken 2013 ve 2016 yıllarında optimum düzeyin altına düştüğü gözlemlenmiştir. $\mathrm{K}$ işletmesinin değerlerine göre tüm yıllar bağlamında değerlerin standardın altında olduğu ve kısa vadeli yükümlülüklerini yerine getirme hususunda sıkıntı yaşayabileceği söylenebilmektedir.

Beaver'in oranlarından sonuncusu olan Net Çalışma Sermayesi/Faaliyet Giderleri oranı, bir işletmenin sahip olduğu net çalışma sermayesiyle faaliyet giderlerini kaç kere ödeyebileceğini göstermektedir. A, E, H ve K işletmelerinin net çalışma sermayesi/faaliyet giderleri oranlarının analize dahil edilen tüm yıllar için negatif gerçekleştiği saptanmıştır. Dolayısıyla bu işletmelerin net çalışma sermayeleriyle faaliyet giderlerini karşılayamadıkları söylenebilir. B işletmesinin değerleri incelendiğinde, 2014 y1lı haricinde negatif değerlere sahip olduğu ve yine 2014 yılı haricinde net ça1ışma sermayesiyle faaliyet giderlerini karşılayamadığ 1 görülmektedir. J işletmesinin net çalışma sermayesi/faaliyet giderleri oran değerleri incelendiğinde, söz konusu oranların 2013 ve 2016 yıllarında negatif gerçekleştiği buna karşın 2012, 2014, 2015 ve 2017 yıllarında pozitif gerçekleştiği görülmektedir. C, D, F, G ve I işletmelerinin değerleri incelendiğinde, analize dahil edilen tüm yıllarda elde edilen net çalışma sermayesi faaliyet giderleri oranlarının pozitif olduğu görülmektedir.

\section{Sonuç}

İşletmelerin, teoride sınırsız olarak kabul edilen ömürlerini devam ettirebilmeleri için işletmelerin amaçları doğrultusunda belirledikleri kara ulaşabilmeleri ve bu kar düzeyini sürdürülebilirlik temelinde korumaları gerekmektedir. Günümüzde teknoloji, ulaşım, harcanabilir gelir ve boş zamanın artması sonucunda çok hızlı bir şekilde büyüyen turizm sektörü, Birleşmiş Milletler Dünya Turizm Örgütü'ne göre yarattığ1 istihdam, hizmet verdiği insan sayıs1, yarattığ1 gelir ve katma değerle dünyanın en büyük sektörü haline gelmiştir (Kandır, Karadeniz, Özmen ve Önal: 2008). Turizm sektörünün en önemli aktörlerinden biri olan konaklama işletmeleri hem kuruluş hem de işletme aşamasında yüksek sermaye yatırımı gerektirmekte ve hem küresel, hem ulusal hem de sektörel gelişmeler finansal performansı olumsuz etkileyebilmektedir. Bu açıdan konaklama işletmelerinin varlıklarını sürdürebilirlik ilkesi çerçevesinde devam ettirmeleri için güçlü bir finansal yapıya sahip olmaları gerekmektedir. Bu bağlamda finansal başarısızlık ve iflas riskinin konaklama işletmeleri açısından da ölçülmesi ve yönetilmesi önem arz etmektedir.

Bu çalışmada, Borsa İstanbul'da işlem gören konaklama işletmelerinde finansal başarısızlık riski Beaver modeliyle ölçülmeye çalışılmıştır. Bu amaçla Borsa İstanbul'da işlem gören 11 konaklama işletmesinin 2012-2017 yıllarına ait finansal tabloları incelenmiştir. Çalışmada elde edilen analiz sonuçlarına göre çalışmaya dahil edilen konaklama işletmelerinin Nakit Akış1/Toplam Borçlar oranları incelendiğinde, analize dahil edilen 11 işletmeden sadece 1 tanesinin (C işletmesi) tüm yıllarda durumunun iyi olduğu ve faaliyetlerinden elde edilen nakitlerle yükümlülüklerini karş1layabildiği; E işletmesinin her yılda optimum düzeyin altında olduğu faaliyetlerinden elde edilen nakitlerle yükümlülüklerini karşılayamadığı; A, G ve D işletmelerinin sadece birer yıl optimum düzeyin altına düştüğü ancak D işletmesinin 2017 yılı değerinin hesaplanamadığı ve B, F, H, I, J ve K işletmelerinin dalgalı bir seyir izlediği ancak genel olarak istenilen düzeyin altında ol- 
duğu ve B işletmesinin 2017 yılı değerinin hesaplanamadığı saptanmıştır. Oranın istenilen düzeyin altında olması, işletmelerin yükümlülüklerini karşılamada yetersiz olduğunu göstermektedir. Beaver modelinde Nakit Akış1/Toplam Borçlar oranı, işletmelerin finansal başarısızlıklarını ölçmede en etkili oran olarak vurgulanmaktadır. Bu nedenle söz konusu oran bağlamında genel olarak BIST konaklama işletmelerinin finansal performanslarının çok iyi olmadığını söylemek mümkündür. Dolayısıyla konaklama işletmelerine; özellikle işletme faaliyetlerinden pozitif bir nakit akışı yaratmaları ve cirodan ziyade kar ve nakit girişlerini arttırmaya yönelik politikalar geliştirmeleri önerilebilir.

Aktif karlılık oranına göre $\mathrm{C}, \mathrm{D}$ ve $\mathrm{F}$ işletmelerinin verileri tüm yıllarda pozitif ve işletmelerin karlılık durumlarının iyi olduğu; $\mathrm{E}$ işletmesinin verilerinin tüm yıllarda negatif olduğu ve karlılığının yetersiz olduğu; $B, G$ ve $H$ işletmelerinin y1llar bağlamında dalgalı bir seyir izlediği görülmektedir. J, A, I ve K işletmelerinin yalnızca birer yıllarında pozitif değerde olduğu geriye kalan yıllarda negatif değerde olduğu sonucuna ulaş1mıştır. Bu oran bağlamında analize dahil edilen konaklama işletmelerinin büyük çoğunluğunun sıkıntılar yaşadığ1 görülmektedir. Dolayısıyla konaklama işletmelerine; maliyet ve gider kontrolünün daha etkin yapılması, fiyatlama stratejilerinin iyi belirlenmesi ve aktif büyüklüğünün optimal düzeyde tutulması önerilebilir.

Finansal kaldıraç oranına göre söz konusu oranın \%50'nin üstüne çıkılması istenen bir durum değildir ve analize dahil edilen işletmelerin genelinin istenilen optimum düzeyin altında olduğu; $\mathrm{E}, \mathrm{G}, \mathrm{H}$ ve $\mathrm{J}$ işletmelerinin son yıllarında istenilen düzeyin üstünde borçlanma gerçekleştirdiği söylenebilir. Bu bağlamda konaklama işletmelerinin finansal kaldıraç düzeylerini genel olarak etkin bir şekilde yönetmeye çalıştıkları görülmektedir. Finansal kaldıraç oranının optimum düzeyden yüksek olan işletmelerin ise finansal kaldıraç düzeylerini daha etkin kullanmaya çalışmalarının, sabit varlıklarının vadelerine uygun olan leasing gibi finansman kaynakları seçmelerinin ve satışlardaki belirsizlik nedeniyle olabildiğince özkaynaklardan yararlanmalarının konaklama işletmelerinin finansal risklerinin azaltılması bağlamında yarar sağlayacağı düşünülmektedir.

Konaklama işletmelerinin cari oranları incelendiğinde, $\mathrm{A}, \mathrm{E}, \mathrm{H}$ ve $\mathrm{K}$ işletmelerinin kısa vadeli yükümlülüklerini karşılayamadıklarını，B ve J işletmelerinin dalgalı seyir izlediklerini ve C, D, F, I ve G işletmelerinin cari oran değerlerinin istenilen düzeyin üzerinde olduğu saptanmıştır. Bu bağlamda analize dahil edilen konaklama işletmelerinde dönen varlıkların ve bu varlıkların finansmanında kullanılan kısa vadeli yabancı kaynak kompozisyonunun likidite, kur ve faiz risklerine uygun olarak belirlenmesinin önemli olacağ düşünülmektedir.

Net Çalışma Sermayesi/Toplam Varlıklar oranı incelendiğinde, $\mathrm{A}, \mathrm{E}, \mathrm{H}$ ve $\mathrm{K}$ işletmelerinin faaliyetlerine devam etmek için ihtiyaç duyduğu net işletme sermaye tutarlarının aktifler içindeki yüzdesinin tüm y1llarda negatif; C, D, F, G ve I işletmelerinin ise pozitif gerçekleştiği ancak oranların çok yüksek olmadığı saptanmıştır. B ve J işletmelerinin ise yıllar itibariyle dalgalı bir seyir izledikleri saptanmıştır. Bahsedilen oranın düşük olması işletmelerin duran varlıklarının bir kısmı da kısa vadeli yabancı kaynaklarla finanse ettiğini göstermektedir ve bu durum işletmelerin günlük faaliyetlerin sürdürülebilirliğini ve likiditesini etkilemektedir. $\mathrm{Bu}$ bağlamda konaklama işletmelerine, dönen varlıklarının vadelerine uygun finansman kaynakları bulmaları, diğer bir ifadeyle minimum finansman dengesini gözetmeleri ayrıca aşırı varlık yatırımlarından kaçınmalar1 önerilebilir.

Net Çalışma Sermayesi/Faaliyet Giderleri oranına ait değerler incelendiğinde; $\mathrm{A}, \mathrm{E}, \mathrm{H}$ ve $\mathrm{K}$ işletmelerinin negatif değerlere sahip olduğu ve bu işletmelerin faaliyet giderlerini karşılamada yetersiz oldukları saptanmıştır. C, D, F, G ve I işletmelerinin değerlerinin ise pozitif olduğu ve bu işletmelerin net çalışma sermayeleriyle faaliyet giderlerini karşılayabildikleri belirlenmiştir. B ve J işletmelerinin de dalgalı bir seyir izledikleri ancak genel olarak negatif değerlere sahip oldukları sonucuna ulaşılmıştır. Burada da konaklama işletmelerine dönen varlıklarının finansmanında minimum finansman dengesini gözetmeleri ve bu bağlamda risk ve karlılık arasında sektörel gelişmelere bağlı olarak bir denge kurmaları önerilebilir. Ayrıca faaliyet giderlerini de (genel yönetim giderleri, satış pazarlama ve dağıtım giderleri gibi) kontrol altında tutmalarının önemli yararlar sağlayacağı düşünülmektedir.

Konuyla ilgili literatür bağlamında konaklama işletmelerinin finansal başarısızlık risklerini ölçen kısıtlı sayıda çalışmaya ulaşılmış ancak Beaver modelini kullanarak BIST Konaklama işletmelerinde finansal başa- 
rısızlık riskini ölçen bir çalışmaya tarafımızca rastlanmamıştır. Bu kapsamda çalışma sonuçlarının literatüre katk1 sağlayacağı düşünülmektedir. Ayrıca Türkiye'deki konaklama işletmeleri bağlamında Beaver modelinin finansal başarısızlık riskinin belirlenmesi açısından nasıl kullanılacağıyla ilgili yatırımcılara ve yöneticilere yararlı bilgiler sunacağı düşünülmektedir. Analizde sadece BIST'te işlem gören halka açık 11 konaklama işletmesinin olması, halka açık olmayan işletmelerden veri elde edilememesi ve zaman sınırının olması çalışmanın kısıtlarını oluşturmaktadır. Ayrıca konaklama işletmelerinin faaliyet alanlarının hepsinin konaklama olmakla birlikte yan faaliyet alanlarının da olduğu (yat marina işletmeciliği, alışveriş, ulaştırma gibi) göz ardı edilememelidir. Gelecekte yapılacak çalışmalarda Türkiye'deki borsada işlem görmeyen konaklama işletmelerinin ve dünyadaki diğer konaklama işletmelerini de dahil ederek daha geniş örneklemi içeren çalışmaların yapılmasının daha genelleştirilebilir sonuçlara ulaşmada faydalı olacağı tarafımızca düşünülmektedir.

\section{Kaynakça}

Aksu, A. (2000). Otel işletmelerinin başarısını etkileyen dış çevre faktörleri. Ballkesir Üniversitesi Sosyal Bilimler Dergisi, 3(4), 269-281.

Aktaş, R. (1991). Endüstri işletmeleri için mali başarısızlık tahmini (Çok boyutlu model uygulaması). Yayımlanmamış doktora tezi, Ankara Üniversitesi: Ankara.

Aktaş, R. (1993), Endüstri İşletmeleri İçin Mali Başarısızlık Tahmini (Çok Boyutlu Model Uygulamasi). Ankara: Türkiye İş Bankası Kültür Yayınları.

Altman, E. I., Hotchkiss, E. (2006), Corporate Financial Distress and Bankruptcy: Predict and Avoid Bankruptcy, Analyze and Invest in Distressed Debt, 3rd Edition. New Jersey: John Wiley\&Sons.

Aydın, N., Başar, M. \& Coşkun, M. (2014), Finansal Yönetim. Ankara: Detay Yayıncılık.

Beaver, W. H. (1966). Financial ratios as predictors of failure. Journal of Accounting Research, 4, 71-11.

Berk, N. (1998), Finansal Yönetim. İstanbul: Türkmen Kitabevi

Ceylan, A. (2001), İşletmelerde Finansal Yönetim. Bursa: Ekin Kitabevi.

Cho, M. H. (1994). Predicting business failure in the hospitality industry: An application of logit model. Unpublished doctoral thesis, Virginia Tech, United States.
Cihangir, M. \& Kara, E. (2014). The reasons for financial failure in accommodation facilities: An analysis of the accommodation facilities in the Cappadoccia Region/Turkey. European Scientific Journal, 10(22), 95115.

Diakomihalis, M. (2012). The accuracy of Altman's models in predicting hotel bankruptcy. International Journal of Accounting and Financial Reporting, 2(2), 96-113.

Elmas, B. (2013). Finansal Analiz Uygulamalarl. Ankara: İmaj Yayınevi.

Gu, Z. \&Goa, L. (2000). A multivariate model for predicting business failures of hospitality firms. Tourism and Hospitality Research: The Surrey Quarterly Review, 2(1), 37-50.

Haber, J. R. \& College, I. (2005). Assesing how bankruptcy prediction models are evaluated. Journal of Business \& EconomicsResearch, 3(1), 87-92.

Jawabreh, O. A., Al Rawashdeh, F. \& Senjelawi, O. (2017). Using Altman's Z-Score model to predict the financial failure of hospitality companies-case of Jordan. International Journal of Information, Business and Management, 9(2), 141-157.

Karaca, S. \& Özen, E. (2017). Financial failure estimation of companies in BIST tourism index by Altman Model and its effect on market prices. BRAND. Broad Research in Accounting, Negotiation, and Distribution, 8(2), 11-23.

KAP, Kamuyu Aydınlatma Platformu (t.y.), 20 Temmuz 2018 tarihinde www.kap.org.tr adresinden alınmıştır.

Kandır, S. Y., Karadeniz, E., Özmen, M. \& Önal, Y. B.(2008). Türk turizm sektöründe büyüme göstergelerinin turizm işletmelerinin finansal performansına etkisinin incelenmesi. Dokuz Eylül Üniversitesi Sosyal Bilimler Enstitüsü Dergisi, 10(1), 211-237.

Kim, H. \& Gu, Z. (2006a). A logistic regression analysis for predicting bankruptcy in the hospitality industry. The Journal of Hospitality Financial Management, 14(1), 1734.

Kim, S. Y. \& Upneja, A. (2013). Predicting restaurant financial distress using decision tree and AdaBoosted decision tree models. Economic Modelling, 36, 354-362.

Kwansa, F. A. \& Parsa, H. G. (1990). Business failure analysis: An events approach. Hospitality Research Journal, 14(2), 23-34.

Lado-Sestayo, R., Otero-González, L., Vivel-Búa, M., \& Martorell-Cunill, O. (2016). Impact of location on profitability in the Spanish hotel sector. Tourism Management, 52, 405-415. 
Mammadli, A. \& Helhel, Y. (2017). Fortune 100 listesinde yer alan turizm şirketleri için Altman Z Skor modeli kullanılarak iflas tahmini. 1. Uluslararası Turizmin Geleceği Kongresi: İnovasyon, Girişimcilik ve Sürdürebilirlik Kongresi (Futourism 2017), MEÜ. Turizm Fakültesi Yayınlarl, 1, 1219-1226.

Mizdrakovic, V., Knezevic, G. \& Stanic, N. (2015). Bankruptcy risk exposure of Serbian hotels in the period 2008-2012. International Conference in Tourism, Singidunum University, Belgrade, 164-167.

Met, Ö. (2013). Turizm ve ă̆ırlama işletmelerinde finansal analiz ve bir uygulama. Ankara: Detay Yayıncılık.

Okka, O. (2009). Analitik finansal yönetim. Ankara: Nobel Akademik Yayıncılık.

Özdemir, F. S. (2011). Finansal raporlama sistemlerinin bilginin ihtiyaca uygunluğu açısından değerlendirilmesi: IMKB şirketlerinde finansal başarısızlık tahminleri yönüyle bir uygulama. Doktora tezi, Ankara Üniversitesi, Ankara.

Pacheco, L. (2015). SMEs probability of default: Thecase of the hospitality sector. Tourism \& Management Studies, 11(1), 153-159.

Poyraz, E. \& Uçma, T. (2006). Türkiye'de faaliyet gösteren ihracatçı sektörlerin mali kriz ortamlarında finansal başarısızlıklarının Altman (Z-Score) modeli yardımıyla ölçülmesi. Muhasebe ve Finanansman Dergisi, (32), 1-10.

Sevil, G., Başar, M. \& Coşkun, M. (Eds.). (2013). Finansal yönetim- II . Ankara: Anadolu Üniversitesi Yayınları.

TDK, Türk Dil Kurumu (t.y.). Büyük Türkçe sözlük. 26 Temmuz 2018 tarihinde www.tdk.gov.tr adresinden alınmıştır.

Türksoy, A. (2007). Konaklama işletmelerinde mali başarısızlığa yol açan etmenler. Ege Akademik Bakış, 7(1), 99115.

Weitzel, W. \&Jonsson, E. (1989). Decline in organizations: A literatüre integrationandextension. Administrative Science Quarterly, 34(1), 91-109.

\section{Extended abstract in English}

Due to the globalization experienced in recent years, the conditions of competition, which are constantly changing and challenging, cause the enterprises, whose life's are considered to be endless, to face difficulties in their existence and even to face financial failure by experiencing financial failure. Lodging companies operating in the tourism sector need a fixed amount of fixed assets at the investment stage and require development and modernization investments during the operational phase; risk and uncertainty. The determination of the effects of the mentioned factors on the lodging companies in advance and taking appropriate measures are considered necessary for the sustainability of the enterprises. In this context, it is of great importance to measure and manage financial failure and bankruptcy risk in terms of lodging companies.

The study examined the financial statements of 11 accommodation companies operating in Istanbul in 2012-2017 in order to measure the financial failure risks of the lodging companies operating in Istanbul in Turkey by using the Beaver model and to determine whether there is a difference between the years 20122017 and the Beaver model was applied. Within the scope of the findings, the financial failure risks of public lodging companies in Turkey have been determined by the relevant years.

According to the results obtained from the study, when Cash Flow/Total debt ratios of lodging companies included in the study are examined, only 1 of the 11 companies included in the analysis (C company) are in good condition in all years and can meet their obligations with the cash obtained from their activities; E has not been able to meet their obligations with; It was determined that the $\mathrm{A}, \mathrm{G}$ and $\mathrm{D}$ companies only fell below the optimum level for one year, but the D's 2017 value cannot be calculated and the $\mathrm{B}, \mathrm{F}, \mathrm{H}, \mathrm{I}, \mathrm{J}$ and $\mathrm{K}$ companies followed a fluctuating course and the $\mathrm{B}$ business value of 2017 could not be calculated. The fact that the ratio is below the desired level indicates that the companies are insufficient to meet their obligations. In the Beaver model, the Cash Flow / Total Debt ratio is emphasized as the most effective rate in measuring the financial failures of companies. For this reason, it is possible to say that the financial performance of BIST lodging companies in general is not very good. Therefore, lodging companies; in particular, it may be advisable to create a positive cash flow from business activities and develop policies to increase profits and cash inflows rather than revenues.

According to the return on asset ratio, C, D and F companies are positive in all years and the profitability of companies is good; The data of $\mathrm{E}$ were negative in all years and the profitability was insufficient; It is observed that $\mathrm{B}, \mathrm{G}$ and $\mathrm{H}$ hold a fluctuating course in the 
context of years. It is concluded that $\mathrm{J}, \mathrm{A}, \mathrm{I}$ and $\mathrm{K}$ companies have positive values only in each year and that they are negative in the remaining years. In the context of this ratio, it is observed that the majority of lodging companies included in the analysis are experiencing difficulties. Therefore, lodging companies; cost and expense control should be made more effectively, pricing strategies should be determined well and the asset size should be kept at optimal level.

According to the financial leverage ratio, it is not desirable to exceed $50 \%$ of the said ratio and the companies included in the analysis are below the desired optimum level; E, G, H and J companies can be said to be above the desired level in the last years. In this context, it is observed that lodging companies are trying to manage financial leverage levels effectively in general. It is thought that the fact that financial leverage ratio of companies with higher than optimum level to use their financial leverage levels more effectively, choosing their financial resources such as leasing which is appropriate to their maturities and benefiting from the shareholders' equity as much as possible due to uncertainty in sales will decrease the financial risks of companies.

When the current ratios of the companies are examined, it is determined that the companies of A, E, H and $\mathrm{K}$ cannot meet their short-term obligations, and that $\mathrm{B}$ and $\mathrm{J}$ companies have fluctuated and that the current values of $\mathrm{C}, \mathrm{D}, \mathrm{F}, \mathrm{I}$ and $\mathrm{G}$ enterprises are above the desired level. In this context, it is considered that it is important to determine the short-term foreign currency composition used in the lodging companies included in the analysis in accordance with the liquidity, exchange rate and interest rate risks used in financing of assets.

When the Net Working Capital/Total Assets ratio is analyzed, the percentage of net working capital amounts required by $\mathrm{A}, \mathrm{E}, \mathrm{H}$ and $\mathrm{K}$ companies to continue their activities is negative in all years; C, D, F, G and I companies were found to be positive but the rates were not very high. B and J have a fluctuating course in years. The fact that the mentioned ratio is low indicates that some of the fixed assets of the companies are financed by current liabilities and this affects the sustainability and liquidity of the enterprises' daily activities. In this context, it may be advisable to provide lodging companies with appropriate sources of financing for $\mathrm{t}$ asset maturities, in other words, to observe the minimum financing balance and to avoid excessive asset investments.

When the values of Net Working Capital/Operating Expenses ratio are examined; A, E, $\mathrm{H}$ and $\mathrm{K}$ companies have negative values and they are found to be insufficient to meet the operating expenses of these companies. It is determined that the values of C, D, F, G and I companies are positive and that these companies can meet the operating expenses with their net working capitals. It is concluded that B and $\mathrm{J}$ have a volatile course but generally have negative values. In this context, it is advisable for the lodging companies to observe the minimum financing balance in the financing of their current assets and to establish a balance between risk and profitability in line with sectoral developments. In addition, keeping the operating expenses under control is expected to provide significant benefits. 